\title{
Pre and Post Effect of Segmental Breathing on Vital Signs by Six Minute Walk Test among Healthy Males and Females
}

\author{
Warisha Sumbul ${ }^{1}$, Ammar Faisal Khan ${ }^{2}$, Asfaque Khan ${ }^{3}$, Zia Abbas Naqvi ${ }^{4}$ \\ ${ }^{1}$ Assistant Professor, T.S. Misra College of Paramedical Sciences, Lucknow \\ ${ }^{2}$ Assistant Professor, Integral Institute of Allied Health Science and Research \\ ${ }^{3} \mathrm{Head}$, Integral Institute of Allied Health Science and Research \\ ${ }^{4}$ Head, T.S. Misra College of Paramedical Sciences, Lucknow \\ Corresponding Author: Zia Abbas Naqvi
}

DOI: https://doi.org/10.52403/ijhsr.20220210

\begin{abstract}
To find out the effectiveness of segmental breathing on vital signs by six-minute walk test among healthy male and females. In this study, 30 subjects were participated. Participant had been confirmed that they fulfill inclusion and exclusion criterion of the study. Study was performed at the Integral university. 30 subject was randomly assigned in this study. Start from assessment of the subjects and vitals checkup and then proceed by 6-minute walk test then again measure vitals and give segmental breathing and rest for 10 minutes then again repeat the procedure of six-minute walk test with pre and post vital measure. The study indicated that the result represents that there has been significant improvement in post segmental breathing 6MWT and also there is significant decrease in rate of perceive exertion by Borg scale. The study concluded that segmental breathing is effective on vitals. There has been significant improvement in after segmental breathing 6MWT and also there is significant decrease in rate of perceive exertion by Borg scale.
\end{abstract}

Key Word- Six-minute walk test (SMWT), segmental breathing. Vital signs, Borg Scale

\section{INTRODUCTION}

The six-minute walk test (6MWT) was first introduced by Lipkin in 1986 as a simple, practical method to evaluate functional capacity. ${ }^{3,4} 6 \mathrm{MWT}$ is regarded as a well-tolerated test, which is more reflective of daily activities compared to other walk tests. ${ }^{3,5}$ Furthermore, the 6MWT is an easily administered test, which only requires a 30-meter corridor with a flat surface, and does not need any special equipment or trained technicians to be performed. ${ }^{1,2,3,4,6}$

The test mainly measures that the distance a person can walk on a hard, flat surface within 6 minutes, simultaneously evaluating the responses of all the systems and mechanisms involved in the exercise, including the respiratory and cardiovascular system, systemic circulation, peripheral circulation, neuromuscular system, and muscle metabolism. ${ }^{3,6}$ According to recent studies, the distance walked in 6 minutes is considered a proper predictor for mortality in different patients. ${ }^{7}$

Monitoring vital signs is integral to patient care in acute hospitals8. Traditionally, the five vital signs are blood pressure, pulse, respiratory rate, oxygen saturation $\left(\mathrm{SpO}_{2}\right)$ and temperature ${ }^{9}$. These signs are universally used to monitor patients' progress. Changing trends in patients' vital signs data can indicate clinical deterioration, which, without identification and intervention, can lead to adverse consequences or death ${ }^{10,11}$. 
Breathing exercise defined as the therapeutic intervention by which purpose full alteration of a given Breathing pattern are categorized as breathing exercises ${ }^{12,15}$. Outcomes have ranged from to increase lung volume, to clear secretions, to improve gas exchange, to control breathlessness, to increase exercise capacity, to reduce blood pressure, to reduce obesity, relaxation response for stress reduction and to control pain in natural child birth ${ }^{13,14,15}$. Breathing exercise can be classified as inspiratory and expiratory. Some of the breathing exercises stresses inspiration thereby increasing lung volume where as others stresses on expiration which assists in clearance of secretions. Breathing exercises can be given if person is conscious and cooperative ${ }^{15}$.

Segmental exercises can be given to increase localized expansion of the lungs ${ }^{16}$. The techniques used with segmental exercises may elicit localized drop in intra pleural pressure $^{17}$ thereby increasing transpulmonary pressure gradient which results in expansion. Manual cues such as vibration or pressure sensation are provided over the regions of chest wall that is not expanding well may also aid in expansion $^{17,18,19}$.

Three types of segmental breathing that target the apical, lateral and posterior segments of the lower lobes are apical expansion exercises, lateral costal breathing and posterior basal expansion exercises ${ }^{14}$. The following technique further stresses inspiration. First squeeze chest during expiration then stretch at the very end of expiration, allow inspiration to occur. Near the end of inspiration apply a series of 3 or 4 gentle stretches rather similar to repeated contractions ${ }^{17}$.

\section{MATERIAL \& METHOD STUDY-DESIGN}

Pre and post test experimental design

\section{STUDY PLACE}

Integral Institute of Medical Sciences, Integral University, Lucknow.

\section{STUDY DURATION}

7 months.

\section{SAMPLE-SIZE}

30 Subjects.

\section{SAMPLE METHOD}

Total of 30 Subjects are taken according to the Inclusion and Exclusion criteria, all subjects satisfied the criteria are allowed to complete the study.

\section{SELECTION CRITERIA INCLUSION CRITERIA}

- The subjects were selected from the population (aged 20 to 40 years) of healthy college students.

- Subjects who are willing in this study.

\section{EXCLUSION CRITERIA}

- History of any cardiovascular disease and pulmonary disease.

- History of any musculoskeletal disease or injury.

- History of any neurological disorder.

- Cardiac and Thoracic Surgeries.

- Seriously Medical Condition.

\section{PROCEDURE}

All the subject were selected on above mentioned inclusion and exclusion criteria, subject were assigned to participation, subjects were explained about the study and informed consent was given individually signed by subjects. Prior to study, pretest assessment was done, baseline data of participant such as weight, height, B.M.I, were documented According to the guidelines published by the American Thoracic Society, all 6MWTs were conducted using a marked hallway $30 \mathrm{~m}$ in length both at the participating in the hospital.

In a period of 6 minutes, the participants were asked to walk back and forth along this hallway as far as possible, at their own best pace but not to run or race. We encouraged subjects with the standardized statements "You're doing well" or "Keep up the good work," but were 
asked not to use other phrases. Subjects were allowed to stop and rest during the test, but were instructed to resume walking as soon as they felt able to do. So dyspnea, as measured with the modified Borg dyspnea scale, systolic and diastolic blood pressure, pulse rate, oxygen saturation, respiratory rate and distance covered were assessed at the start and end of the 6-min walk test. Subjects were also asked at the end of the walk whether they had experienced any of the. Following symptoms: dyspnea, chest pain, lightheadedness, or leg pain.

After $6 \mathrm{~min}$ walk test segmental breathing (perform all four segmental breathing exercises start with apical expansion, lateral costal expansion, right middle lobe expansion then posterior basal expansion.) The following technique further stresses inspiration. First squeeze chest during expiration then stretch at the very end of expiration, allow inspiration to occur. Near the end of inspiration apply a series of 3 or 4 gentle stretches rather similar to repeated contractions.

After a 10 min break we again start 6 min walk test to measure the difference between pre and post effect of segmental breathing.

\section{DATA ANALYSIS}

Thirty subjects participated in this study. Correlation test was use to check any effect of demographic data on variables. And the frequency and percentage was calculated for qualitative data means $( \pm \mathrm{SD})$ was calculated for continuous data paired ttest was used to compare the continuous variable between two 6MWT before and after segmental breathing, $\mathrm{P}$ value less than 0.05 was taken as criteria for rejecting null hypothesis.

\section{RESULT}

Table 1: Distribution of Study subjects according to personal characteristic.

\begin{tabular}{|l|l|}
\hline Variables & $\mathrm{N}=30$ \\
\hline Age & 25.66667 \\
\hline Gender & \\
\hline Male & 14 \\
\hline Female & 16 \\
\hline
\end{tabular}

Table 1 depicts that the mean age of study subjects is 25.66 . Out of 30 subjects 16 are female and 14 are male

Table: 2 Distribution of Study subjects according to BMI
\begin{tabular}{|l|l|l|l|l|}
\hline NORMAL & UNDER & OVER \\
WEIGHT & WEIGHT & WEIGHT & \\
\hline BMI & 24 & 3 & 3 & 22.26 \\
\hline
\end{tabular}

Table2 Depicts that out of 30 subject $80 \%$ have normal BMI, $10 \%$ underweight and $10 \%$ overweight. And the mean BMI of study subjects is 22.26

\section{DEFFERENCE BETWEEN BEFORE SEGMENTAL BREATHING RESTING AND POST VITALS OF 1st 6 MIN WALK TEST}

\begin{tabular}{|l|l|l|l|l|}
\hline Variables & Resting (R) & Post 1 $^{\text {st }}$ 6MWT (P) & \multicolumn{2}{|l|}{ Significance } \\
\hline SBP & $121.53 \pm 11.19$ & $134.53 \pm 11.21$ & $\mathrm{t}=-8.26$ & $\mathrm{p}=<.0001$ \\
\hline DBP & $81.16 \pm 8.98$ & $86.36 \pm 8.31$ & $\mathrm{t}=-4.30$ & $\mathrm{p}=0.0002$ \\
\hline HR & $87.63 \pm 9.76$ & $110.50 \pm 16.33$ & $\mathrm{t}=-9.85$ & $\mathrm{p}=<.0001$ \\
\hline RR & $18.93 \pm 1.46$ & $19.53 \pm 0.86$ & $\mathrm{t}=-3.53$ & $\mathrm{p}=0.0014$ \\
\hline SPO2 & $97.80 \pm 0.55$ & $98.36 \pm 0.61$ & $\mathrm{t}=-4.57$ & $\mathrm{p}=<.0001$ \\
\hline
\end{tabular}

TABLE 3 shows the difference between resting and post 6MWT changes on vitals. Whereas the $\mathrm{t}$ - test (paired) shows that there is significant difference between pre -post test vitals-

\section{DIFFERENCE BETWEEN AFTER SEGMENTAL BREATHING AND POST VITALS OF 2ND 6MWT VITALS.}

\begin{tabular}{|l|l|l|l|l|}
\hline Variables & After Segmental Breathing (S) & Post2nd 6MWT (PS) & \multicolumn{2}{|c|}{ Significance } \\
\hline SBP & $121.96 \pm 12.86$ & $131.30 \pm 10.48$ & $\mathrm{t}=-6.27$ & $\mathrm{p}=<.0001$ \\
\hline DBP & $80.46 \pm 7.26$ & $82.66 \pm 7.97$ & $\mathrm{t}=-1.26$ & $\mathrm{p}=0.2189$ \\
\hline HR & $96.03 \pm 10.58$ & $114.73 \pm 14.00$ & $\mathrm{t}=-9.81$ & $\mathrm{p}=<.0001$ \\
\hline RR & $19.46 \pm 0.89$ & $19.53 \pm 0.86$ & $\mathrm{t}=-1.00$ & $\mathrm{p}=0.3256$ \\
\hline SPO2 & $97.90 \pm 0.40$ & $98.50 \pm 0.50$ & $\mathrm{t}=-6.60$ & $\mathrm{p}=<.0001$ \\
\hline
\end{tabular}


TABLE 4 shows the difference between after segmental breathing and post 2nd $6 \mathrm{MWT}$ changes on vitals. Whereas the $\mathrm{t}-$ test shows that there is significant difference between pre -post test vitals-

5. COMPARISON BETWEEN VITALS BEFORE SEGMENTAL BREATHING 1st 6MWT AND AFTER SEGMENTAL BREATHING 2nd 6 MWT.

\section{1- COMPARISON BETWEEN RESTING VARIABLES AND AFTER}

SEGMENTAL BREATHING VARIABLES.

\begin{tabular}{|l|l|l|c|c|}
\hline Variables & Resting (R) & After Segmental Breathing $($ S) & \multicolumn{2}{|c|}{ Significance } \\
\hline SBP & $121.53 \pm 11.19$ & $121.96 \pm 12.86$ & $\mathrm{t}=-0.27$ & $\mathrm{p}=0.7913$ \\
\hline DBP & $81.16 \pm 8.98$ & $80.46 \pm 7.26$ & $\mathrm{t}=0.56$ & $\mathrm{p}=0.5780$ \\
\hline HR & $87.63 \pm 9.76$ & $96.03 \pm 10.58$ & $\mathrm{t}=-9.85$ & $\mathrm{p}=<.0001$ \\
\hline RR & $18.93 \pm 1.46$ & $19.46 \pm 0.89$ & $\mathrm{t}=-2.80$ & $\mathrm{p}=0.0089$ \\
\hline SPO2 & $97.80 \pm 0.55$ & $97.90 \pm 0.40$ & $\mathrm{t}=-1.0$ & $\mathrm{p}=0.3256$ \\
\hline
\end{tabular}

TABLE 5.1- shows the comparison between resting and after segmental breathing vitals. Whereas the $\mathrm{t}-$ test shows that there is no significant difference between vitals-

\section{2-COMPARISON BETWEEN POST 1ST 6MWT VARIABLES AND AFTER SEGMENTAL BREATHING VARIABLES.}

\begin{tabular}{|l|l|l|l|l|}
\hline Variables & Post $^{\text {st }}$ 6MWT $(\mathbf{P})$ & After Segmental Breathing $(\mathbf{S})$ & \multicolumn{2}{|l|}{ Significance } \\
\hline SBP & $134.53 \pm 11.21$ & $121.96 \pm 12.86$ & $\mathrm{t}=9.36$ & $\mathrm{p}=<.0001$ \\
\hline DBP & $86.36 \pm 8.31$ & $80.46 \pm 7.26$ & $\mathrm{t}=4.23$ & $\mathrm{p}=0.0002$ \\
\hline HR & $110.50 \pm 16.33$ & $96.03 \pm 10.58$ & $\mathrm{t}=8.38$ & $\mathrm{p}=<.0001$ \\
\hline RR & $19.53 \pm 0.86$ & $19.46 \pm 0.89$ & $\mathrm{t}=1.00$ & $\mathrm{p}=0.3256$ \\
\hline SPO2 & $98.36 \pm 0.61$ & $97.90 \pm 0.40$ & $\mathrm{t}=4.06$, & $\mathrm{p}=0.0003$ \\
\hline
\end{tabular}

TABLE 5.2- shows the comparison between post 1st 6MWT and after segmental breathing vitals. Whereas the $\mathrm{t}-$ test shows that there is significant difference between vitals-

\section{3-COMPARISON BETWEEN POST 1ST 6MWT VARIABLES AND POST 2ND 6MWT VARIABLES.}

\begin{tabular}{|l|l|l|l|l|}
\hline Variables & Post 1 $^{\text {st }}$ 6MWT (P) & Post 2nd 6MWT (PS) & \multicolumn{2}{l|}{ Significance } \\
\hline SBP & $134.53 \pm 11.21$ & $131.30 \pm 10.48$ & $\mathrm{t}=2.18$ & $\mathrm{p}=0.0374$ \\
\hline DBP & $86.36 \pm 8.31$ & $82.66 \pm 7.97$ & $\mathrm{t}=2.62$ & $\mathrm{p}=0.0139$ \\
\hline HR & $110.50 \pm 16.33$ & $114.73 \pm 14.00$ & $\mathrm{t}=-1.60$ & $\mathrm{p}=0.1194$ \\
\hline RR & $19.53 \pm 0.86$ & $19.53 \pm 0.86$ & $\mathrm{t}=0.00$, & $\mathrm{p}=1.0000$ \\
\hline SPO2 & $98.36 \pm 0.61$ & $98.50 \pm 0.50$ & $\mathrm{t}=-1.16$, & $\mathrm{p}=0.2550$ \\
\hline
\end{tabular}

TABLE 5.3- shows the comparison between post 1st 6MWT and post 2nd 6MWT vitals. Whereas the $\mathrm{t}-$ test shows that there is no significant difference between vitals-

\section{4-COMPARISON BETWEEN POST 1ST 6MWT RPE AND POST 2ND 6MWT RPE

\begin{tabular}{|l|l|l|l|l|}
\hline Variables & Post 1 & 6MWT $(\mathbf{P})$ & Post 2nd 6MWT (PS) & Significance \\
\hline RPE & $0.98 \pm 0.40$ & $0.85 \pm 0.32$ & $\mathrm{t}=2.50$ & $\mathrm{p}=0.0182$ \\
\hline
\end{tabular}

TABLE 5.4- shows the comparison between post 1st 6MWT and post 2nd 6MWT RPE. Whereas the $\mathrm{t}-$ test shows that there is significant difference between RPE-

\section{5-COMPARISON BETWEEN POST 1ST 6MWT DISTANCE AND POST 2ND 6MWT DISTANCE}

\begin{tabular}{|l|c|l|l|r|}
\hline Variables & Post 1 $^{\text {st }}$ 6MWT (P) & Post 2nd 6MWT (PS) & \multicolumn{2}{|l|}{ Significance } \\
\hline DIS & $582.73 \pm 52.12$ & $603.30 \pm 52.43$ & $t=-11.00$ & $p=<.0001$ \\
\hline
\end{tabular}

TABLE 5.5- shows the comparison between post 1st 6MWT and post 2nd
6MWT DISTANCE. Whereas the $\mathrm{t}$ - test shows that there is significant difference.- 


\section{DISCUSSION}

This Study was conducted to determine the effectiveness of segmental breathing on vitals by 6 minute walk test among healthy males and females by observing 7 different parameters (Systolic Blood Pressure, Diastolic Blood Pressure, Heart Rate, Respiratory Rate, Oxygen Saturation, Rate of Perceive Exertion, and distance cover during walk).

Total 30 healthy subjects (14 Males \& 16 Females) of Integral Institute of Medical Sciences Integral University, at Lucknow were considered for study with prior information \& consent of the subject. All 30 subject were taken as per inclusion and exclusion criteria, all 30 subject those who satisfied the criteria were included in the study.

Follow the procedure in sequence as per guidelines described, start from assessment of the subjects and pre vitals checkup and then proceed by 6 minute walk test then again measure vitals then give segmental breathing and rest for 10 minutes then again repeat the procedure of six minute walk test with pre and post vital measure.

Result obtained in Table 1 depicts the personal characteristic wise distribution of study subjects. Findings show that the mean age of study subjects is 25.66 . Out of 30 subjects 16 are female and 14 are male.

Results obtained in Table2 Depicts that out of 30 subject $80 \%$ have normal BMI, $10 \%$ underweight and $10 \%$ overweight. The table also represents the mean Body Mass Index BMI of study subjects. The mean BMI is $22.26( \pm 3.18)$.

Results obtained in Table 3 represent the difference between resting and post 6MWT changes on vitals. Whereas the $\mathrm{t}-$ test shows that there is significant difference between pre -post test vitals. T-test shows there is significance difference in all variables. In SBP, $\mathrm{HR}$ and $\mathrm{SPO} 2$ $(\mathrm{p}=<.0001)$, in DBP $(\mathrm{p}=0.0001)$, and in $\mathrm{RR}$ $(\mathrm{p}=0.0014)$.

Results obtained in Table 4 represent the difference between after segmental breathing and post $2^{\text {nd }} 6 \mathrm{MWT}$ changes on vitals. Whereas the $\mathrm{t}-$ test shows that there is significant difference between pre -post test vitals. T-test shows there is significance difference in three variables SBP, HR, and, SPO2. And no significant difference in remaining two that is DBP, RR. In SBP, $\mathrm{HR}$, and SPO2 $(\mathrm{p}=<.0001)$, in DBP $(\mathrm{p}=0.2189)$, and in $\mathrm{RR}(\mathrm{p}=0.3256)$.

Results obtained in table 5.1 represent the comparison between resting and after segmental breathing vitals. Whereas the $t$ - test shows that there is no significant difference between vitals. T-test shows there is no significance difference in three variables SBP, DBP, and, SPO2. And significant difference in remaining two that is HR, RR. In SBP $(p=0.7913)$, in DBP $(\mathrm{p}=0.5780)$, in $\mathrm{SPO} 2(\mathrm{p}=0.3256)$, and in HR $(\mathrm{p}=<.0001)$, in $\mathrm{RR}(\mathrm{p}=0.0089)$.

Results obtained in table 5.2 represent the comparison between post $1 \mathrm{st}$ 6MWT and after segmental breathing vitals. Whereas the $\mathrm{t}$ - test shows that there is significant difference between vitals. T-test shows there is significance difference in four variables SBP, DBP, HR, and, SPO2. And no significant difference in remaining one that is RR. In SBP, HR ( $\mathrm{p}=<.0001)$, in DBP ( $\mathrm{p}=0.0002)$, in SPO2 ( $\mathrm{p}=0.0003)$, and in $R R(p=0.3256)$.

Results obtained in table 5.2 represent the comparison between post $1 \mathrm{st}$ 6MWT and post 2nd 6MWT vitals. Whereas the $t$ - test shows that there is no significant difference between vitals. T-test shows there is significance difference in two variables SBP, DBP, And no significant difference in remaining three that is $\mathrm{HR}$, $\mathrm{RR}, \mathrm{SPO} 2$. In SBP $(\mathrm{p}=0.0374)$, in DBP $(\mathrm{p}=0.0139)$, in $\mathrm{HR}(\mathrm{p}=0.1194)$, in $\mathrm{RR}$ $(\mathrm{p}=1.0000)$, in SPO2 $(\mathrm{p}=0.2550)$.

Results obtained in table 5.3 represent the comparison between post 1 st $6 \mathrm{MWT}$ and post $2^{\text {nd }} 6 \mathrm{MWT}$ RPE. Whereas the $\mathrm{t}$ - test shows that there is significant difference between RPE. T-test shows there is significant difference between post $1^{\text {st }}$ 6MWT and post 2nd 6MWT RPE $(\mathrm{p}=0.0182)$. 
Results obtained in table 5.4 represent the comparison between post 1 st $6 \mathrm{MWT}$ and post $2^{\text {nd }} 6 \mathrm{MWT}$ distance. Whereas the $\mathrm{t}$ - test shows that there is significant difference. T-test shows there is significant difference between post 1 st 6MWT and post 2nd 6MWT DIS $(\mathrm{p}=<.0001)$.

Finally the result represent that there has been significant improvement in after segmental breathing 6MWT and also there is significant decrease in rate of perceive exertion by Borg scale.

Sambhaji B. Gunjal et al 2015 reported that his study concludes that the segmental breathing exercises have better effect on chest expansion and pulmonary function than deep breathing exercises ${ }^{20}$.

Nield et al,.2007 conducted a randomized, control study, Changes in dyspnea and functional performance was assessed by modified Borg after 6 minute walk distance (6MWD), shortness of breath Questionnaire. Finally concluded that breathing exercise provided sustained improvement in exertional dyspnea and physical function. ${ }^{21}$

\section{CONCLUSION}

After analyzing the result, it can be concluded that segmental breathing is effective on vitals. There has been significant improvement in after segmental breathing post $2^{\text {nd }} 6 \mathrm{MWT}$ and also there is significant decrease in rate of perceive exertion by Borg scale.

\section{Source Of Funding- Nil}

Acknowledgement: None

\section{Conflict of Interest: None}

\section{Ethical Approval: Approved}

\section{REFERENCES}

1. ATS statement: guidelines for the sixminute walk test. ATS Com- mittee on Proficiency Standards for Clinical
Pulmonary Function Laboratories. Am J Respir Crit Care Med 2002;166(1):111-117.

2. Solway S, Brooks D, Lacasse Y, Thomas S. A qualitative systematic overview of the measurement properties of functional walk tests used in the cardiorespiratory domain. Chest 2001;119(1):256-27

3. Ghofraniha L, Dalir Sani Z, Vakilian F, Khajedalooyi M, Javid Arabshahi Z. The Six-minute Walk Test (6MWT) for the Evaluation of Pulmonary Diseases. J Cardiothorac Med. 2015; 3(2): 284-287.

4. Venkatesh N, Thanikachalam S, Satyanarayana Murthy J, Arun Maiya, Senthil Kumar T, Sridevi S. Six minute walk test: a literary review. Sri Ramachandra Journal of Medicine. 2011;4:30-4.

5. Solway S, Brooks D, Lacasse Y, Thomas S. A qualitative systematic overview of the measurement properties of functional walk tests used in the cardiorespiratory domain. Chest. 2001; 11:9256-70.

6. ATS Committee on Proficiency Standards for Clinical Pulmonary Function Laboratories. ATS statement: guidelines for the six-minute walk test. Am J Respir Crit Care Med. 2002; 166:111-7.

7. Dourado VZ. Reference equations for the 6 - minute walk test in healthy individuals. Arq Bras Cardiol. 2011.

8. Stewart JV.Vital Signs and Resusccitation. Texas: Landes Bioscience,2003.

9. Elliott M, Coventry A. Critical care: the eight vital signs of patient monitoring. $\mathrm{Br} \mathrm{J}$ Nurs2012;21:621-5.

10. Hillman KM, Bristow PJ, Chey Tet al.Antecedents to hospital deaths Intern Med J2001;31:343-8.

11. Schein RM, Hazday N, Pena $M$ et al.Clinical antecedents to inhospitalcardiopulmonary arrest.Chest 1990;98:1388-92.

12. Subin Solomen, breathing technique a review,IJPESH 2015; 2(2): 237-241 (C) 2015.

13. Claudia Levenson R. Breathing exercises: In Cynthia Coffin Zadai. Pulmonary Management in Physical Therapy. 1st ed. NY (USA): Churchill Livingstone Inc., 1992.

14. Mounika. 6 Yoga breathing techniques for weight loss. Stylecraze. com. 2014. Available from URL: 
http://www.stylecraze.com/articles/6-yogabreathingtechniques-for-weight-loss.

15. Mila Diamond. Lose weight by breathing...Really! Beautiful confident you! 2012. Available from URL: http://www.womensperfectbody.com/fatloss /lose-weight- by-proper-breathing.

16. Kisner C, Colby L. Therapeutic exercise. Philadelphia: F.A. Davis, 1996.

17. Hough A. Physiotherapy in respiratory care. Cheltenham: Nelson Thornes, 2001.

18. Derenne J, Macklem PT, Roussos CH. The Respiratory muscles: Mechanics, Control and Pathophysiology. Part I. Am Rev Respir Dis. 1978; 118:119-133.

19. Wetzel JL. Management of respiratory dysfunction. In: Edelle C. field, Editor. Spinal cord Injury rehabilitation FA Davis, 2009, 337-392.

20. Sambhaji B. Gunjal et al 2015 the segmental breathing exercises have better effect on chest expansion and pulmonary function than deep breathing exercises, International Journal of Health Sciences \& Research (www.ijhsr.org) 234 Vol.5; Issue: 7; July 2015

21. Nield MA, Soo Hoo GW, Roper JM, Santiago S. Efficacy of pursed-lips breathing: a breathing pattern retraining strategy for dyspnea reduction. J Cardiopulm Rehabil Prev. 2007 JulAug;27(4):237-44. doi: 10.1097/01.HCR.0000281770.82652.cb. PMID: 17667021.

How to cite this article: Warisha Sumbul, Ammar Faisal Khan, Asfaque Khan et.al. Pre and post effect of segmental breathing on vital signs by six minute walk test among healthy males and females. Int J Health Sci Res. 2022; 12(2): 76-82. DOI: https://doi.org/10.52403/ ijhsr.20220210 